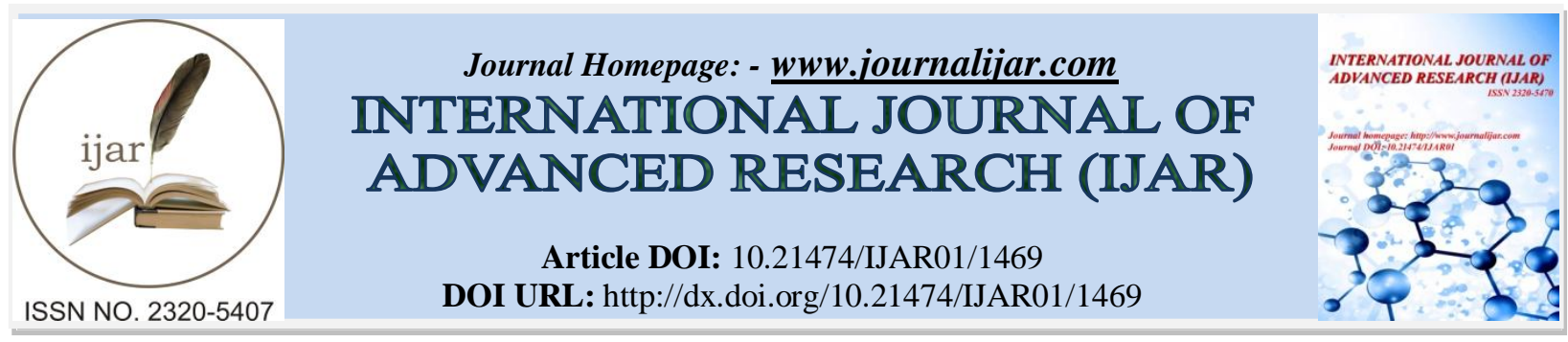

RESEARCH ARTICLE

\title{
MODIFIED TRADITIONAL SNACK (MULTIGRAIN KARANJI) FOR TYPE 2 DAIBETES MELLITUS
}

\section{Mrudula Gaikwad and Dr. Rupali Sengupta.}

Department of Clinical Nutrition and Dietetics, Dr.BMN College of Home Science 338, R.A. Kidwai Road Matunga Mumbai- 400019

\section{Manuscript Info}

Manuscript History

Received: 12 July 2016

Final Accepted: 22 August 2016

Published: September 2016

Key words:-

Diabetes Mellitus, Phoenix dactylifera,

Traditional snack.
Abstract

The product is a Traditional Diwali snack preferred during other festivities also. The original Traditional snack is high in calories, fats, and made form refined flour. The Traditional snack recipe was Modified for Type 2 Diabetes Mellitus patients by replacing all the key ingredients with Multigrain flour, nuts, sesame seeds and Phoenix dactylifera (Black dates) were used instead of sugar for the sweetness. Also the product was baked instead of deep frying like Traditional recipe. Sensory Evaluation was conducted using likert scale. Compared to the Traditional snack it was observed that the Modified Multigrain Baked Karanji could be a good snack option for patients with Type 2 Diabetes Mellitus as it was high in protein, fiber, and fats, it was rich in omega 3 fatty acids and also the Phoenix dactylifera (Black dates) imparted enough sweetness to satiate Diabetes Mellitus patients cravings or urge to eats sweet.

Copy Right, IJAR, 2016,. All rights reserved.

\section{Introduction:-}

Diabetes is a group of metabolic diseases characterized by hyperglycemia resulting from defects in insulin secretion, insulin action, or both. The chronic hyperglycemia of diabetes is associated with long-term damage, dysfunction, and failure of different organs, especially the eyes, kidneys, nerves, heart, and blood vessels.

Type 2 Diabetes Mellitus is a form of diabetes, which accounts for $\sim 90-95 \%$ those with diabetes, previously referred to as non-insulin-dependent diabetes, type 2 diabetes, or adult-onset diabetes, encompasses individuals who have insulin resistance and usually have relative (rather than absolute) insulin deficiency At least initially, and often throughout their lifetime, these individuals do not need insulin treatment to survive.

The modified traditional Product was developed to fulfill the urge of the diabetes patients who want to eat sweet but they are unable as the Traditional snack is very unhealthy and may raise the sugar levels of the diabetes mellitus patients as it is made with refined flour and sugar.

In a study were association between refined grain consumption with insulin resistance and the metabolic syndrome in an urban south Indian population was studied. 2042 individuals aged 20 years were randomly selected from Chennai Urban Rural Epidemiological Study (CURES). Mean refined grain intake was 333g/d (46.9\% of total calories). After adjustments for age, sex, body mass index, metabolic equivalent, total energy intake, and other dietary factors, higher refined grain intake was significantly associated with higher waist circumference $(8 \%$ higher for highest vs the lowest quartile, $\mathrm{P}$ for trend , .0001). Other parameters like systolic blood pressure, diastolic blood 
pressure, fasting blood glucose, serum triglyceride, low density lipoprotein cholesterol and insulin resistance were also considered. Compared with participants in the bottom quartile, participants in the highest quartile of refined grain intake were significantly more likely to have metabolic syndrome (odds ratio, 7.83; 95\% confidence interval, 4.72-12.99). Higher intake of refined grains was associated with insulin resistance and the metabolic syndrome in this population of Asians Indians who habitually consume high carbohydrate diets. (Ganeshan, 2009)

The modified traditional product was a modification of traditional snack that is very much relished during the festivities by Indians. It is made in a traditional way by using only dry coconut, refined flour, and semolina and sugar and deep fried. Considering the Diabetes Mellitus population in India and their desire to indulge in sweets during the festivities this healthy, nutritious modified snack was developed which was high in fiber, protein and fats and also contains omega 3 fatty acids. It was much more nutritious than the deep fried Traditional snack.

\section{Methodology:-}

* The main ingredient of the Traditional snack refined flour and sugar was replaced with multigrain flour (wheat, Ragi, oats and Bengal gram flour).

* Sugar was replaced with Phoenix dactylifera (Black dates) which contain sugar and also contain vitamin A, thiamine, and complex of vitamin $\mathrm{B}$, folate, vitamin $\mathrm{C}$, and vitamin $\mathrm{E}$, vitamin $\mathrm{K}$, along with minerals like calcium, iron, magnesium, manganese, phosphorus, potassium, sodium and zinc.

* The modified snack was baked instead of deep frying which made it less in calories.

* The filling of the snack was made using almonds, sesame seeds, and walnuts.

* Almonds are rich in biotin, manganese, copper, vitamin E, vitamin B12, phosphorous, magnesium, molybdenum, and fiber.

* Walnuts are an excellent source of omega-3 fatty acids. People with diabetes often have high triglycerides and low HDL levels. Omega-3 fatty acids can help lower triglycerides and raise HDL.

* Sesame seeds contain "phytates" which one of the most potent antioxidant \& one of the most potent anticancer substance.

* Oil was used for greasing and a small amount was added to the flour to make it crisp.

Table 1:- Standardization of the Food Product.

\begin{tabular}{|c|c|c|c|}
\hline \multicolumn{2}{|c|}{ MULTIGRAIN BAKED KARANJI } & \multicolumn{2}{c|}{ TRADITIONAL RECIPE } \\
\hline INGREDIENTS & AMOUNTS(gms) & INGREDIENTS & AMOUNTS(gms) \\
\hline Wheat flour & 10 & Maida & 25 \\
\hline Ragi flour & 5 & Corn flour & 20 \\
\hline Oats & 5 & Rawa & 10 \\
\hline Besan flour & 5 & Dry coconut & 10 \\
\hline Almonds & 7.5 & Sugar & 30 \\
\hline Walnuts & 7.5 & Oil & 5 \\
\hline Til seeds & 5 & Almonds & 10 \\
\hline Black dates & 5 & Cashew nuts & Ghee \\
\hline Oil & 10 & & \\
\hline
\end{tabular}


Figure 1:- Method of preparation.

In a bowl mix all the flours add $5 \mathrm{ml}$ of hot oil and make dough out of it and cover with a muslin cloth.

For the filling roast the almonds, walnuts and sesame seeds. Pound all of them in a pounder and add chopped dates and give a proper mix.

Divide the dough into equal four portions and roll small chapatti out of it. Put the mixture onto one side and fold it and give it the shape of the semicircle.

Grease a baking tray with oil place the karanji in the tray and apply oil.

\section{Bake at 180 degree Celsius for 15-20mins.}

Comparison of the Nutritive Value of the Traditional snack KARANJI and modified Traditional snack recipe MULTIGRAIN KARANJI.

Table 2:- Traditional Snack karanji.

\begin{tabular}{|l|l|l|l|l|l|l|}
\hline INGREDIENTS & $\begin{array}{l}\text { AMOUNT(G } \\
\text { MS) }\end{array}$ & $\begin{array}{l}\text { ENERGY( } \\
\text { KCAL) }\end{array}$ & CHO(GMS) & $\begin{array}{l}\text { PROTIEN(G } \\
\text { MS) }\end{array}$ & $\begin{array}{l}\text { FATS } \\
\text { (GMS) }\end{array}$ & TDF \\
\hline Maida & 25 & 87 & 18.4 & 2.75 & 0.2 & - \\
\hline Corn flour & 5 & 17 & 3.3 & 0.5 & 0.18 & 0.5 \\
\hline Rawa & 20 & 70 & 15 & 2.08 & 0.16 & - \\
\hline Dry coconut & 10 & 66 & 1.84 & 0.68 & 6.25 & - \\
\hline Sugar & 10 & 40 & 10 & - & - & - \\
\hline Oil & 30 & 270 & - & - & 30 & - \\
\hline Almonds & 5 & 33 & 0.5 & 1.04 & 2.9 & - \\
\hline Cashew nuts & 5 & 30 & 1.11 & 1.06 & 2.34 & - \\
\hline Ghee & 10 & 90 & - & - & 10 & - \\
\hline & TOTAL & 703 & 50.15 & 8.11 & 52.03 & 0.5 \\
\hline
\end{tabular}

Table 3:- Modified Product (Multigrain Baked Karanji).

\begin{tabular}{|l|l|l|l|l|l|l|}
\hline INGREDIENTS & $\begin{array}{l}\text { AMOUNT(G } \\
\text { MS) }\end{array}$ & $\begin{array}{l}\text { ENERGY } \\
\text { (KCAL) }\end{array}$ & CHO(GMS) & $\begin{array}{l}\text { PROTIEN } \\
\text { (GMS) }\end{array}$ & $\begin{array}{l}\text { FATS } \\
\text { (GMS) }\end{array}$ & TDF \\
\hline Wheat flour & 10 & 35 & 7.12 & 1.21 & 0.15 & 1.25 \\
\hline Ragi flour & 5 & 16 & 3.6 & 0.36 & - & 0.57 \\
\hline Oats & 5 & 16 & 3.6 & 0.36 & ------ & \\
\hline Besan flour & 5 & 18 & 3 & 1.04 & 0.2 & 1.41 \\
\hline Almonds & 7.5 & 49 & 1.05 & 2.09 & 5.89 & - \\
\hline
\end{tabular}




\begin{tabular}{|l|l|l|l|l|l|l|}
\hline Walnuts & 7.5 & 52 & 1.1 & 1.56 & 6.45 & - \\
\hline Til seeds & 5 & 28 & 1.25 & 0.91 & 2.16 & 0.84 \\
\hline Black dates & 7.5 & 20 & 4.75 & - & - & 1.1 \\
\hline Oil & 10 & 90 & - & - & 10 & - \\
\hline & TOTAL & 324 & 25.5 & 7.53 & 25 & 5.17 \\
\hline & & & & & & \\
\hline
\end{tabular}

Table 4: - Comparison between Traditional and Modified Product.

\begin{tabular}{|l|l|l|l|}
\hline NUTRIENT & UNIT & TRADITIONAL PRODUCT & MODIFIED PRODUCT \\
\hline Energy & $\mathrm{kcal}$ & 703 & 324 \\
\hline Protein & $\mathrm{gm}$ & 8.11 & 7.53 \\
\hline Carbohydrate & $\mathrm{gm}$ & 50.15 & 25.5 \\
\hline Fat & $\mathrm{gm}$ & 52.03 & 25 \\
\hline TDF & $\mathrm{gm}$ & 0.5 & 5.17
\end{tabular}

Calculation of the Nutritive Value was done using Nutritive Value of Indian Foods. (Gopalan, 2012)

\section{Sensory evaluation:-}

Multigrain baked karanji was subjected for sensory evaluation based on 5 point scale for the appearance, taste, texture, color and presentation. The score was based on the criteria, 5- very good, 4- good, 3- average, 2-poor, and 1very poor. There was a gradual improvement in the following weeks. The product was rated very well in the $3^{\text {rd }}$ week.

Figure 2:-

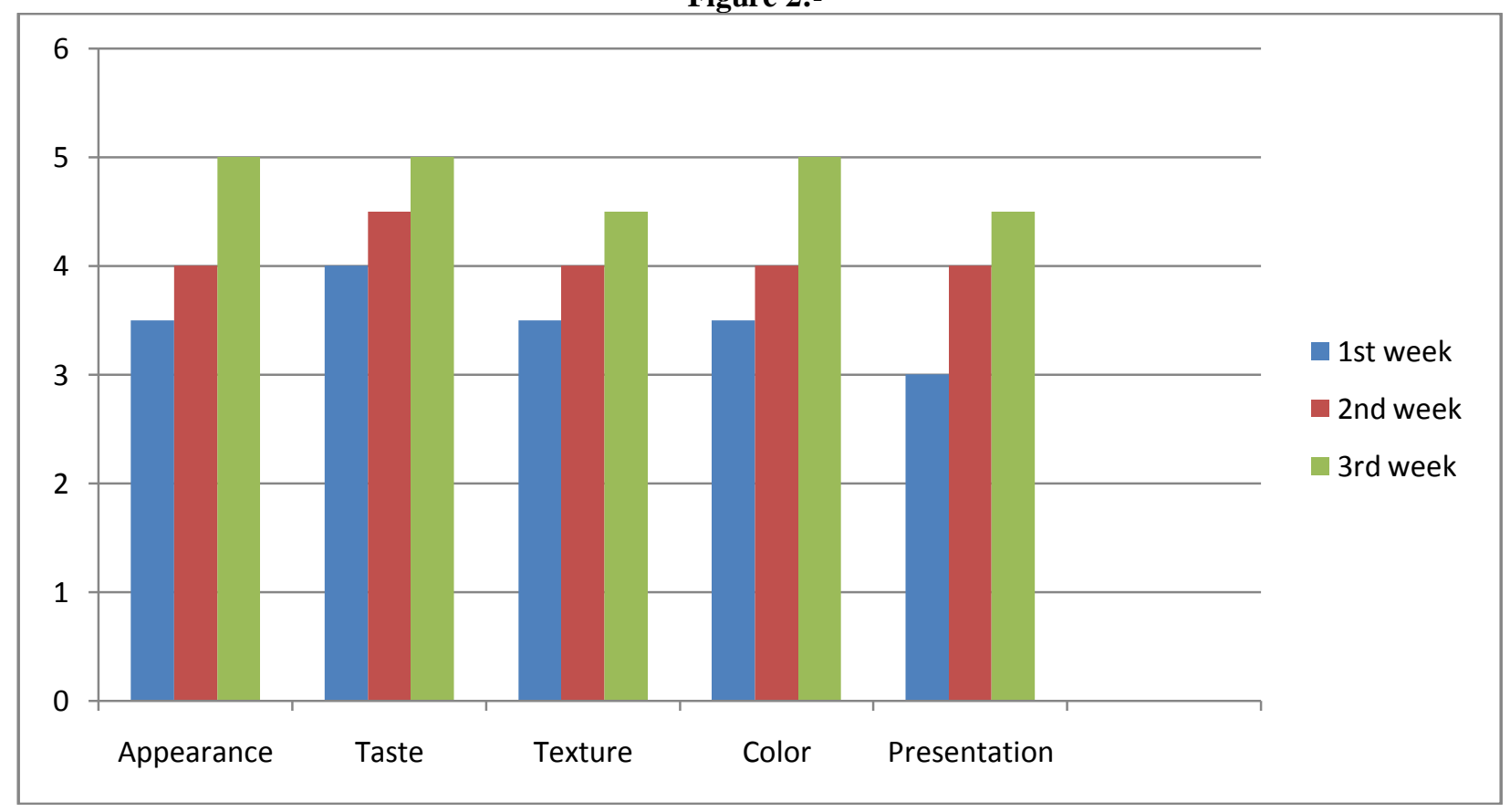

\section{Result:-}

The modified product had high fiber, good amount of proteins. It was high in Fat but low compared to the traditional food. The modified product was also low in GI because it had a multigrain flour (wheat flour, oats, Besan flour, Ragi flour etc) which are complex carbohydrates and also high in fiber. The nuts like almonds, walnuts, and sesame seeds are good source of omega 3 fatty acids and antioxidants which are very beneficial for the type 2 diabetes, Compared to the traditional recipe it was only high in total fat with no dietary fiber and simple sugar in the form of refined flour and sugar which is not a healthy option for the diabetics. 


\section{Discussion:-}

The 2005 and 2010 Dietary Guidelines for Americans (DGA) recommend that whole grains account for at least half of 6 to 11 daily grain servings to reduce the risk of chronic diseases, including T2D, obesity, and heart disease.

In a study association between whole and refined grain intake and risk for type 2 diabetes was studied 51529 male health professional were followed for $<12$ years. Intake of whole grains and refined grains was measured every 4 years by food frequency questionnaire. The results of 1197 cases of incident type 2 diabetes after adjustment for age, physical activity, cigarette smoking, family history of diabetes and fruit, vegetable and energy intakes the relative risk of type 2 diabetes was $0.58(95 \% \mathrm{cl} 0.47,0.70$ :P for trend <0.0001) comparing the highest with lowest quintile of whole grain intake. It concluded that in men diet high in whole grain is associated with decreased risk of type 2 diabetes that may be mediated by cereal fiber. (Fung, 2002)

In a randomized, crossover study were 13 patients with type 2 diabetes were assigned to follow 2 diets each for 6 weeks, a diet containing moderate amounts of fiber (total $28 \mathrm{~g}$, soluble fiber $8 \mathrm{~g}$ and insoluble fiber $16 \mathrm{~g}$ ) recommended according to $\mathrm{ADA}($ American Diabetes Association) and high fiber diet (total 50g, soluble fiber 25g and insoluble fiber 25g), During the $6^{\text {th }}$ week of high fiber diet as compared to ADA diet there was decrease in mean pre prandial plasma glucose concentration by $13 \mathrm{mg} / \mathrm{dl}$ and mean daily urinary glucose excretion was $1.3 \mathrm{~g}$ lower. The high fiber diet lowered the area under the curve for 24 hours plasma glucose and insulin concentration. (Chandala, 2000)

Two studies met the whole-grain definition criteria defined by the FDA. Evidence for the association between wholegrain intake and T2D risk reduction was shown in one large, well designed prospective cohort of females only [Nurses' Health Study (NHS)]. No prospective study in males was found. Although the NHS was a carefully designed and well conducted study, the absence of any confirmatory prospective study limits the confidence that whole grains reduce the incidence of T2D. Nonetheless, the data from the NHS allow one to make a comparison between the benefit of whole grain compared with cereal fiber in reducing the risk of diabetes. Daily intakes of bran, cereal fiber, and whole grains were 9.6-12 g, $12 \mathrm{~g}$, and $36.9-45.6 \mathrm{~g}$ in the highest quintiles and $0.6-1.1 \mathrm{~g}, 1 \mathrm{~g}$, and $3.2-5.5 \mathrm{~g}$ in the lowest quintiles, respectively. These data suggest that daily intakes of $8-11 \mathrm{~g}$ of cereal fiber and $34-$ $40 \mathrm{~g}$ of whole grains provide comparable RR values. One cross-sectional study showed no association with risk factors related to T2D. Evidence for the association between whole-grain intake and development of T2D was considered as level C. (Susan, 2013)

The health advantages of whole grains are largely associated with consuming the entire whole-grain "package," which includes vitamins (B vitamins, vitamin E), minerals (iron, magnesium, zinc, potassium, selenium), essential fatty acids, photochemical (physiologically active components of plants that have functional health benefits) and other bioactive food components. Most of the health-promoting substances are found in the germ and bran of a grain kernel and include resistant starch, oligosaccharides, inulin, lignans, phytosterols, phytic acid, tannins, lipids, and antioxidants, such as phenolic acids and flavonoids. 8 It is believed that these nutrients and other compounds, when consumed together, have an additive and synergistic effect on health.

In this study, nut consumption was inversely associated with risk of type 2 diabetes after adjustment for age, BMI, family history of diabetes, physical activity, smoking, and alcohol and total energy intake. Also, peanut butter consumption was associated with a lower risk of developing diabetes. The relative risk (RR) of developing diabetes was reduced $27 \%$ in those who ate nuts 5 or more times per week compared with those who rarely or never ate nuts. The effect seemed the most marked in those with a normal body weight in whom the RR was reduced further to $45 \%$ in the $\geq 5$ servings/wk group. High intake of nuts was not associated with overweight, nut consumption $\geq 5$ times per week tended to reduce the RR of CHD. (David, 2007)

Almonds appear to not only decrease after-meal rises in blood sugar, but also provide antioxidants to mop up the smaller amounts of free radicals that still result.

Furthermore, a study by Scott et al. in patients with either metabolic syndrome or type 2 diabetes demonstrated a similar effect to that in the study by Lovejoy et al. . Subjects were randomized to a standard AHA diet (15\% protein, $30 \%$ fat, 15\% MUFA) vs. a higher protein (25\%), high-MUFA (22\%) diet for 42 wk. To replace other high-MUFA foods, almonds were given during the last $24 \mathrm{wk}$ to the high-MUFA group. Blood lipids and fasting glucose did not differ between the groups. However, patients in both groups improved their glycemic control, possibly related to the weight loss observed with both treatments. (Cyril, 2010) 
Walnuts are an excellent source of omega-3 fatty acids. People with diabetes often have high triglycerides and low HDL levels. Omega-3 fatty acids can help lower triglycerides and raise HDL, so eating walnuts or foods high in omega-3s may help people with diabetes.

In a study 55 living men and women were assigned to one of three groups low fat, modified low fat, and walnut specific (30g/day). Dietary intakes and clinical outcomes were measured at baseline, at 3 and 6 months. Dietary goals were $>10 \%$ energy from saturated fat, $7-10 \%$ from PUFA and $n-6: n-3$ ratio $>10$. At baseline dietary intakes were not significantly different between groups. No group and few individuals were consuming PUFA (10\%). At 3 and 6 months macronutrient levels were similar among groups. Only in the walnut group all fatty acid intake targets $(\mathrm{P}<0.1)$ was achieved and had greatest proportion of subjects achieving targets $(\mathrm{P}<0.5)$. Walnuts were the main source of dietary fat $(31 \%), \mathrm{n}-3$ PUFA(50\%). Regular inclusion of walnuts in the context of total diet would not have adverse effects on energy intakes and total fat intakes of Type 2 diabetes mellitus. (Gillen, 2005)

Dates come from the date palm. Dates contain sugar and also contain vitamin A, thiamine, and complex of vitamin $\mathrm{B}$, folate, vitamin $\mathrm{C}$, and vitamin $\mathrm{E}$, vitamin $\mathrm{K}$, along with minerals like calcium, iron, magnesium, manganese, phosphorus, potassium, sodium and zinc.

Composition analysis was carried out for five types of dates (Tamer stage). The weights of the flesh of the dates equivalent to $50 \mathrm{~g}$ of available carbohydrates were calculated. The study subjects were thirteen healthy volunteers with a mean $( \pm \mathrm{SD})$ age of $40.2 \pm 6.7$ years and ten participants with type 2 diabetes mellitus (controlled on lifestyle measures and/or metformin) with a mean $\mathrm{HbA1c}( \pm \mathrm{SD})$ of $6.6 \pm(0.7 \%)$ and a mean age $( \pm \mathrm{SD})$ of $40.8 \pm 5.7$ years. Each subject was tested on eight separate days with $50 \mathrm{~g}$ of glucose (on 3 occasions) and $50 \mathrm{~g}$ equivalent of available carbohydrates from the 5 varieties of date (each on one occasion). Capillary glucose was measured in the healthy subjects at $0,15,30,45,60,90$ and $120 \mathrm{~min}$ and for the diabetics at $0,30,60,90,120,150$ and $180 \mathrm{~min}$. The glycemic indices were determined as ratios of the incremental areas under the response curves for the dates compared to glucose. Statistical analyses were performed using the Mann-Whitney U test and repeated measures analysis of variance.

The results show low glycemic indices for the five types of dates included in the study and that their consumption by diabetic individuals does not result in significant postprandial glucose excursions. These findings point to the potential benefits of dates for diabetic subjects when used in a healthy balanced diet. (Juma, 2011)

Since ancient times, sesame has been considered a rare herb that can treat or prevent diseases. In recent studies, sesame and its ligands have been shown to have beneficial effects in treating, preventing, and ameliorating diabetes. The combined consumption of sesame oil and glibenclamide not only reduced the blood glucose levels significantly (36\% in treatment compared to no treatment) but also decreased plasma total cholesterol, and this significantly improved the condition of subjects with type 2 diabetes.

Sesame seeds contain some phytosterols that are similar to cholesterol \& when present in the diet in sufficient amounts are believed to reduce blood levels of cholesterol. Sesame seeds contain "phytates" which one of the most potent antioxidant \& one of the most potent anticancer substance. (Lin, 2014).

\section{Reference:-}

1. Chandala, M. (2000). Beneficial effects of High Dietary fiber intake in patients with type 2 Diabetes Mellitus . New Englang Journal of Medicine , 342:1392-8.

2. Cyril. (2010). Nuts, Metabolic syndrome and diabetes. British journal of Nutrition, 104,465-473.

3. David. (2007). Possible benefits of Nuts in Type 2 Diabetes. The Journal of Nutrition .

4. Fung, T. T. (2002). Whole grain intake and the risk of type 2 diabetes; a prespective study in men. American Society for Clinical Nutrition, 535-540.

5. Ganeshan. (2009). Refined grian consumption and the metabolic syndrome in urban Asians Indians(Chennai Urban Rural Epidemiology Study 57). 675-681.

6. Gillen. (2005). Sturctured dietary advice incorpoating walnuts achieves optimal fat and energy balance in patients with type 2 diabetes mellitus. American dietetic association, 105:1087-96.

7. Gopalan. (2012). Nutritive Value Of Indian Foods. Hyderabad: National Institute of Nutrition. 
8. Juma. (2011). Glycemic indice of five varieties of dates in halthy and diabetic subjects. Nutrition journal , $1475-2891$.

9. Lin, Y. C. (2014). Type 1 Diabetes, Cardiovascular Complications and sesame . Journal of Traditional and Complementray Medicine, 36-41.

10. Susan. (2013). Consumption of cereal fiber, mixtures of whole grains and bran and whole grains and risk reduction in Type 2 Diabetes Mellitus, Obesity and Cardiovascular disease. American Journal of Clinical Nutrition . 